\title{
Bolt connection behaviour of the cold-formed steel joint
}

\author{
Sabril Haris*, Hazmal Herman, Zaidir, and Rendy Thamrin \\ Civil Engineering Department, Andalas University, Kampus Unand Limau Manis, Padang, Indonesia
}

\begin{abstract}
This paper presents an experimental study of bolt connection behaviour of the cold-formed steel joint. A 5-mm bolt was used to combine two channel sections. The size of channel section was $75 \mathrm{~mm}$ height, $35 \mathrm{~mm}$ width and $0.75 \mathrm{~mm}$ thickness. Tension test was conducted to obtain material characteristics of the channel section. Two type of connections were observed: Connection Type-1 that back-to-back channel sections were joined on their web directly, and Connection Type-2 that two channel sections were joined on their flanges through a same-size channel connector. The specimen was pulled by an increasing monotonically load. It was found that ultimate condition of the joint occurred when the bolt was split due to shear failure and the bolt was rotated because the hole size increased; these two failure modes are covered in the Indonesian and Australian/New Zealand cold-formed steel codes. The ultimate loads from the test were compared to analytical calculations using the formulae provided in the codes. The analytical calculation predicted the resistances conservatively within the range of $4-22 \%$.
\end{abstract}

\section{Introduction}

Cold-formed materials have been applied in various areas including automotive industries and building constructions. Nowadays, cold-formed steel has become an alternative material to replace timber for the short span roof on the residential house or even substitute conventional steel material for the longer span roof on the industrial building. According to $\mathrm{Yu}$ in [1], cold-formed steel material has several advantages in light weight, high strength and stiffness, uniform quality and noncombustibility.

Most of the cold-formed steel structural elements are assembled by using screws because of simplicity and fast installation process; use of bolt as fastener is found rarely. Although use of screws is more favourable due to method and time consideration than bolt, some potential failures may limit bolt's capacity to resist the load. Unlike bolt, screw has no nut which can prevent excessive rotation of the bolt and separation of the connection due to increasing of the hole size such as reported in [2 - 4]. Experimental results of screw connection which improper installation was presented in [5]. A gap between two layer elements on the screw connection generated additional bending and torque moments which could decrease its resistance.

Application of bolt connection on the simple moment frame was investigated in [6]. The bolts of $12 \mathrm{~mm}$ diameter were used at the beam-column joints and the supports. Indentation around the hole was observed without failure of the bolts. Kulkarni and Vaghe [7] conducted experimental tests of bolt connections on the cold-formed channel section using packing plate; diameter of bolt was $12 \mathrm{~mm}$. Failure only occurred on the packing plate and the cold-formed section. The resistance of $12 \mathrm{~mm}$ bolt was presumed to be much stronger than the resistance of the channel section, so that the bolts did not failure during the tests.

In this paper, experimental tests were conducted for connection of light gauge steel using $5 \mathrm{~mm}$ bolt(s). Two type of connections were observed, i.e.: Connection Type1 which joined on their webs directly and Connection Type- 2 which joined on their flanges through a same-size channel connector. Experimental tests were conducted by subjecting the specimens to axial load with a constant speed until failure occurred. Type of ultimate conditions when the maximum load reached were observed. The experimental results were compared to the analytical calculation using formulae in the codes.

\section{Experimental Study}

Experimental tests were carried out for the channel section joint connected by bolts. Nominal size of the channel section was $75 \mathrm{~mm}, 35 \mathrm{~mm}$, and $0.75 \mathrm{~mm}$ in height, width, and thickness, respectively. Two type of connections were observed, i.e.: Connection Type-1 and Connection Type-2 (Figure 1). There were three similar specimens for each connection type. Connection Type-1 was two channel sections which were set in back-to-back position and joined on their webs directly using one bolt. In the second type, two channel sections were joined by two bolts on their flanges using a same-size connector channel. In total, four bolts were used in this connection type.

\footnotetext{
${ }^{*}$ Corresponding author: sabril_haris_hg $@$ ft.unand.ac.id
} 


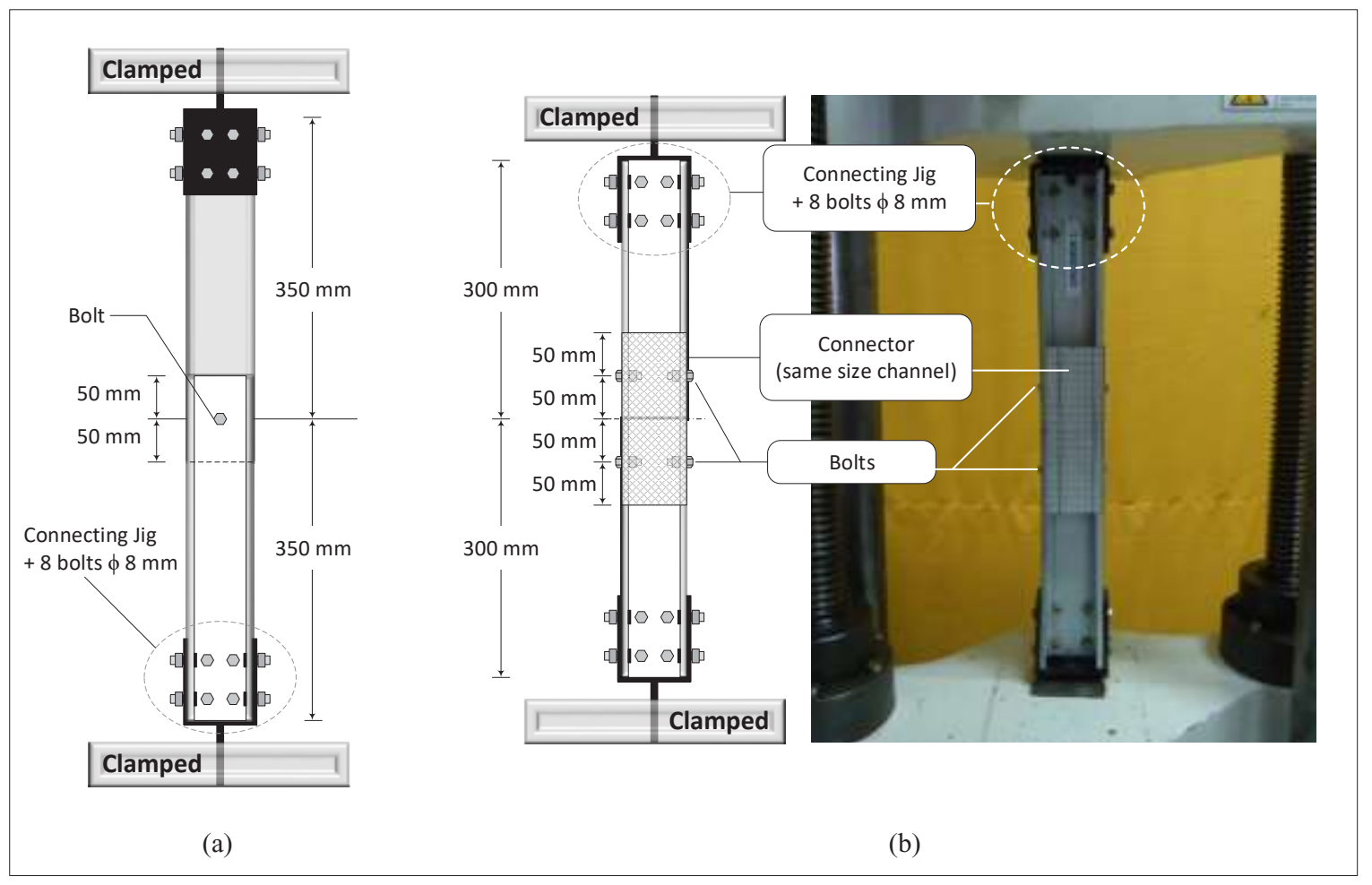

Fig 1. Illustration for two type of connections: (a) Connection Type-1, (b) Connection Type-2 and photo of the specimen

Each end of the specimen was clamped to the Universal Testing Material through a connecting jig. Eight bolts of $8 \mathrm{~mm}$ in diameter were used to fasten securely the ends of specimen and the connecting jigs; failures did not occur on this transition area. The specimen was subjected by axial tension load which increased monotonically until failure. The speed of loading was 2 $\mathrm{mm}$ per minute. The load and displacement data during the test was displayed on the screen, so that loaddisplacement curve could be observed directly.

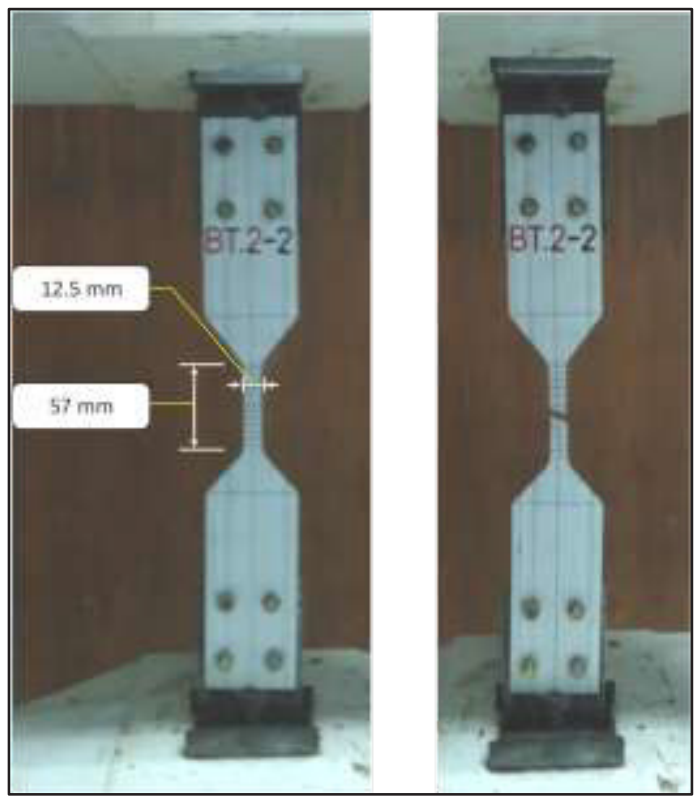

Fig 2. The specimen before and after tensile test
Cold-formed steel used in this study was a typical material which available and applied widely in residential construction in Indonesia. Properties of material were obtained through tensile test which refer to the standard for metals test [8]. Specimen for tensile test was taken from section web of the channel section; the channel was cut to form a profile of specimen as shown in Figure 2. The observed tensile zone defined in the reference was 57 $\mathrm{mm}$ in length and $12.5 \mathrm{~mm}$ in width. Both ends of the specimen were prolonged and linked to connecting jig with 4 bolts. The tensile specimen was pulled by the Universal Testing Machine with a constant speed of $2 \mathrm{~mm}$ per minute.

Typical ultimate condition was found on the tensile specimen that diagonal fracture occurred suddenly at the observed tensile zone, i.e. at the specimen width of 12 $\mathrm{mm}$. In general, the ultimate stress was slightly higher than the yield stress with the maximum rupture strain was $3.51 \%$ (see Table 1). Modulus of elasticity was assumed to be $\mathrm{E}=200,000 \mathrm{MPa}$, a standard modulus for a typical cold-formed steel material. Diameter of the bolts used at the joint for both connection types was $5 \mathrm{~mm}$; the bolt's grade was A307 with minimal tensile strength of $420 \mathrm{MPa}$ [9].

Table 1. Tensile test results

\begin{tabular}{|c|c|c|c|}
\hline $\begin{array}{c}\text { Connection } \\
\text { Type }\end{array}$ & $\begin{array}{c}\text { Yield } \\
\text { Stress } \\
\text { (fy, MPa) }\end{array}$ & $\begin{array}{c}\text { Ultimate } \\
\text { Stress } \\
(\mathbf{f u}, \mathbf{M P a})\end{array}$ & $\begin{array}{c}\text { Ultimate } \\
\text { Strain }\end{array}$ \\
\hline 1 & 578.9 & 581.9 & $2.63 \%$ \\
\hline 2 & 589.9 & 589.9 & $3.51 \%$ \\
\hline
\end{tabular}




\section{Connection Test Results and Discussion}

\subsection{Ultimate Condition}

Ultimate condition for Connection Type-1 which two channel sections (CS-1 and CS-2) were joined with one bolt is shown in Figure 3. It was observed that the channel sections displaced away, and centre of the holes were no longer coincide at the ultimate state. The holes were dented by the bolt and their shape became oval. Indentation around the hole and displacement of the specimen indicated that the bolt was rotated and tilted before it failed. Failure at the connection occurred when the bolt was split at the shear plane, i.e. contact plane between two channel sections.
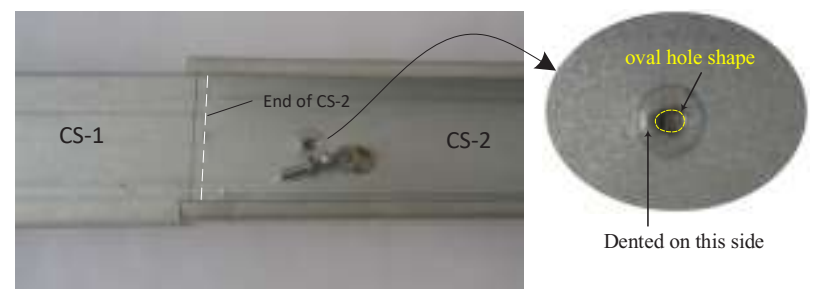

Fig 3. Ultimate state for Connection Type-1
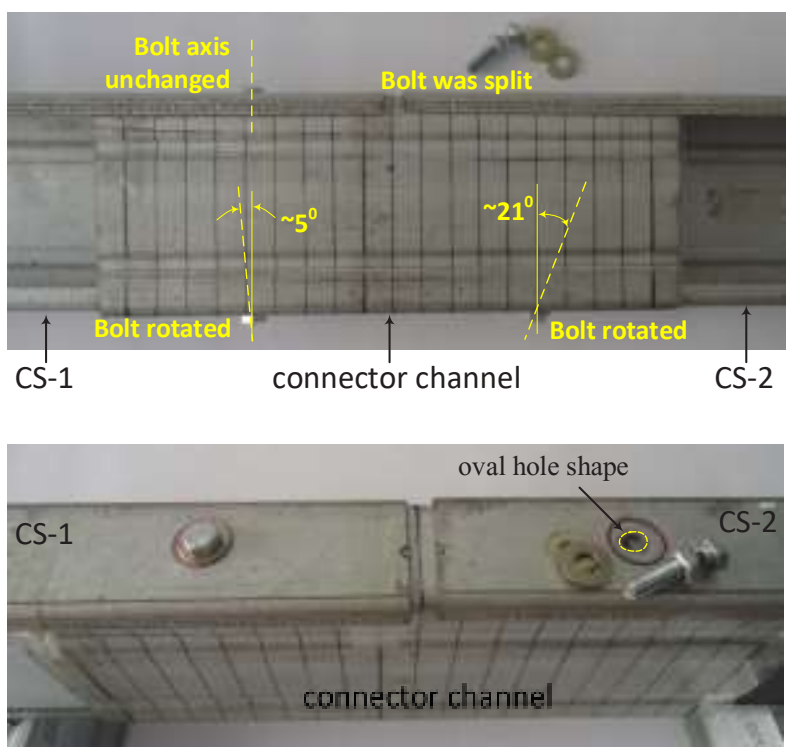

Fig 4. Ultimate state for Connection Type-2

Ultimate condition for Connection Type-2 is illustrated in Figure 4. There was four bolts in the connection system for which two bolts kept each channel section joining to the connector channel. However, all four bolts determined failure of the connection independently; failure on one bolt might cause failure of the connection system. It was observed from three specimens of Connection Type-2 that the ultimate condition occurred when one bolt was split, while other three bolts were not failure: two bolts were rotated and one bolt's axis was unchanged. Condition of these three bolt's axis indicated the stages of bolt before failure was initiated by rotation of the bolt. Regarding shape of the hole, similar condition was found. The hole became oval due to indentation.

\subsection{Load-Displacement Curve}

Response of the specimens to the subjected load are shown in Figure 5. It was noted that the loads used in the curve for Connection Type-2 (Figure 5.b) was a half of the total loads, in order to compare them to Connection Type-1 curves. In general, all load-displacement $(P-\delta)$ curves showed similar tendency that the load increased almost linearly and dropped quickly after maximum load reached. The average ultimate loads $\left(P_{u}\right)$ for Connection Type- 1 and Type- 2 were $4.77 \mathrm{kN}$ and $5.50 \mathrm{kN}$, respectively. Other data related to load and displacement are collected in Table 2.
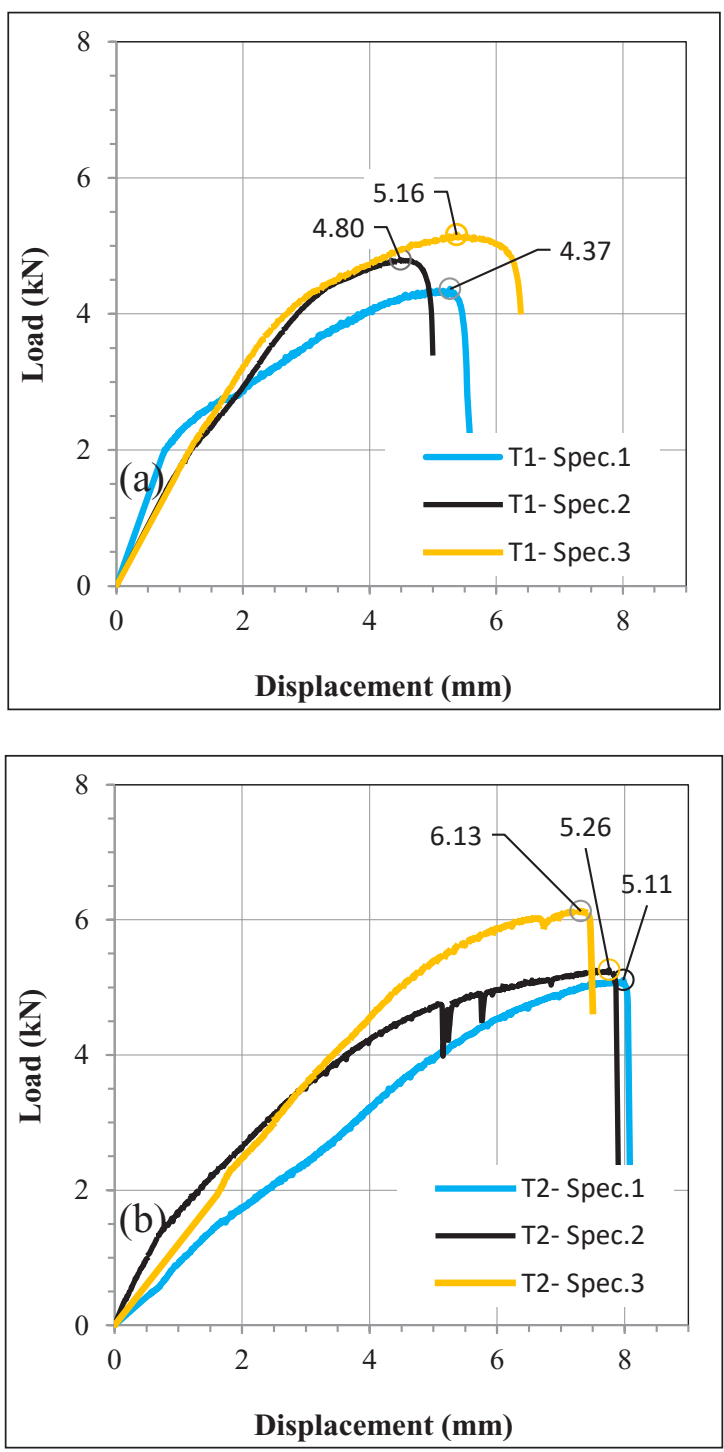

Fig 5. Load-Displacement Curve for: (a) Connection Type-1, (b) Connection Type-2 
Table 2. Load and displacement data

\begin{tabular}{|c|c|c|c|c|c|c|}
\hline \multirow{2}{*}{ Type } & \multirow{2}{*}{ Specimen Id } & \multicolumn{3}{|c|}{ Experimental } & \multicolumn{2}{|c|}{ Calculated $P_{u}$} \\
\hline & & $\begin{array}{c}P_{u} \\
(\mathrm{kN})\end{array}$ & $\begin{array}{c}\delta_{u}^{*} \\
(\mathbf{m m})\end{array}$ & $\begin{array}{c}P_{u-\text { avrg }} \\
(\mathbf{k N})\end{array}$ & $\begin{array}{c}P_{u \text {-bearing }} \\
(\mathrm{kN})\end{array}$ & $\begin{array}{l}P_{u \text {-shear }} \\
(\mathbf{k N})\end{array}$ \\
\hline 1 & $\begin{array}{l}\text { T1-Spec.1 } \\
\text { T1-Spec.2 } \\
\text { T1-Spec.3 }\end{array}$ & $\begin{array}{l}4.37 \\
4.80 \\
5.16\end{array}$ & $\begin{array}{l}5.27 \\
4.52 \\
5.37\end{array}$ & 4.77 & 3.92 & 6.55 \\
\hline 2 & $\begin{array}{l}\text { T1-Spec.1 } \\
\text { T1-Spec.2 } \\
\text { T1-Spec.3 }\end{array}$ & $\begin{array}{l}5.11 \\
5.26 \\
6.13\end{array}$ & $\begin{array}{l}7.98 \\
7.76 \\
7.31\end{array}$ & 5.50 & 3.92 & 6.55 \\
\hline
\end{tabular}

* displacement at $P_{u}$

\subsection{Analytical Calculation}

From the experimental tests, two conditions were identified when the ultimate condition occurred on the connection system, i.e.: indentation on the hole and shear failure of the bolt. Indonesian National Standard for Light Gauge Steel [10] and Australian/New Zealand Standard for Cold-formed Steel Structures [11] provide formula to calculate connection resistance for the state of indentation on the hole (bearing) and shear failure of the bolt, i.e.:

$$
\text { Bearing } \quad: V_{b}=a C d_{f} t f_{u}
$$

Shear failure : $V_{f v}=0.62 f_{u f}\left(n_{n} A_{c}+n_{x} A_{o}\right)$

where:

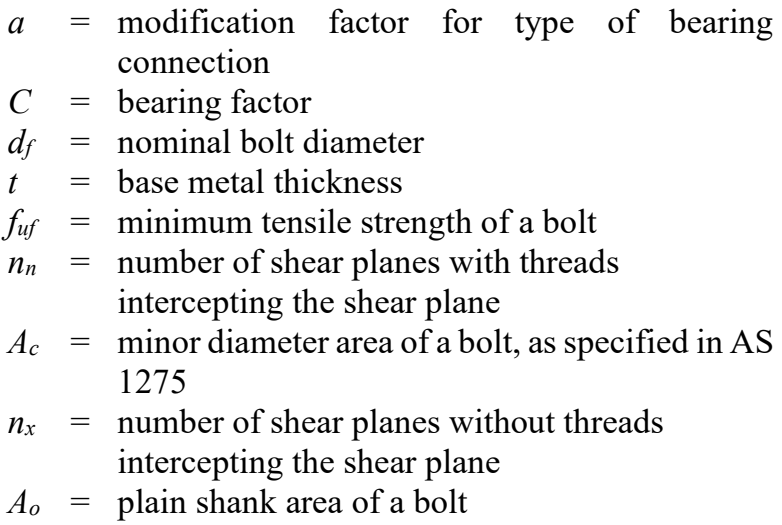

Using appropriate value for constants and parameters in Eq. 1 and Eq.2, resistances due to indentation around the hole and bolt shear were calculated, and it yielded the resistances of $6.55 \mathrm{kN}$ and $3.92 \mathrm{kN}$, respectively. These resistances indicated that the connection will be dissemble at the minimum load of $3.92 \mathrm{kN}$ because of the shear failure on the bolt.

\subsection{Discussion}

The shear failure on the bolt determined the ultimate condition of the connection because its resistance lower than the resistance due to indentation around the hole. It means the connection will be failed because of the bolt splitting, and thus indentation around the hole should not occur. However, test results showed that indentation around the hole still occurred although the ultimate condition was determined by shear failure on the bolt. The hole on the channel section was still prone to be indented. It caused change of shape and dimension of the hole. The hole shape became bigger and changed to oval form. The bolt was then rotated and tilted following direction of the applied load as shown in Figure 4.

The ultimate loads from the experimental test and analytical calculation were compared through following steps. For Connection Type-1, each ultimate experimental load in Table 2 was compared to analytical bearing resistance. It is because one bolt involved in this connection. For Connection Type-2, for which two bolts involved, the ultimate load in Table 2 was multiplied by two. The result was then compared to the sum of bearing and shear failure resistances which met failure condition of the bolts on the connection: one bolt was split and one bolt indented the hole.

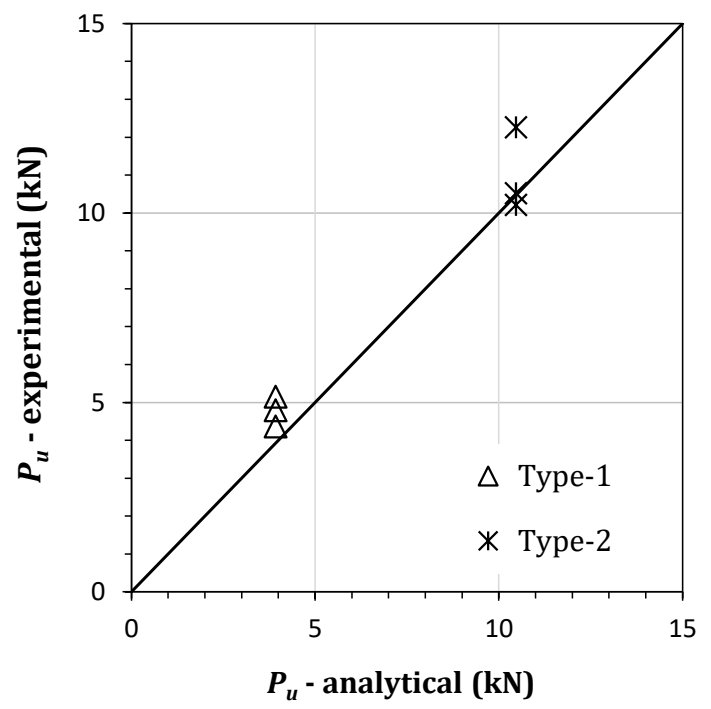

Fig 6. Comparison between experimental results and analytical calculations

Comparison between experimental results and analytical calculations is presented in Figure 6. It shows 
that the analytical formula conservatively predict the experimental results. In average, the bolt resistances from the test were $22 \%$ and $4 \%$ greater than analytic for Connection Type-1 and Type-2, respectively.

\section{Conclusion}

Experimental results of bolt connection behaviour on the cold-formed steel joints has been conducted in this study. For two different connection type, similar ultimate conditions on the specimens loading were found, i.e.: shear failure of the bolt and indentation on the hole. Analytical formula defined greater resistance due to indentation than resistance due to shear failure which indicated that indentation on the hole will not initiate if shear failure on the bolt occur. However, indentation on the hole still occurred and the hole shape was changed become oval. This condition caused the centre of the holes became no longer coincide and the bolt was rotated. Comparing to the experimental results, analytical calculation predict lower resistances within the range of 4 $-22 \%$.

\section{References}

1. W.W. Yu. Cold-Formed Steel Design. (John Wiley and Sons Inc, New York, 2000)

2. S. Haris, H. Herman. Experimental study of connection behavior using screws on light gauge structural elements (in Indonesian). Proceeding of Annual Civil Engineering Seminar 2015. Pekanbaru, Indonesia, pp 390-396, 2015.
3. S.S. Fairuz, L.H. Ho. Influence of Screw Spacing on the Strength of Self-Drilling Screw Connection for the High Strength Cold-Formed Steel. Adv. Mat. Research 712-715, pp 1054-1057. 2013.

4. R.M. Francka, R.A. LaBoube. Screw Connections Subject to Tension Pull-Out and Shear Forces. Proceeding of Twentieth International Specialty Conference on Cold-Formed Steel Structures. St. Louis, Missouri, pp 635-651. 2010.

5. Bambach, M.R. \& Rasmussen, K.J.R. Behavior of Self-Drilling Screws in Light-Gauge Steel Construction. J Str Eng 133, pp 895 - 898. 2007.

6. B.A. Ali, S. Saad, M.H. Osman. (2010). ColdFormed Steel Frame with Bolted Moment Connections. Int J Civil and Struct. Eng. 1 (3), pp 534-544. 2010

7. R.B. Kulkarni, V.M. Vaghe. Experimental study of bolted connections using light gauge channel sections and packing plates at the joints. Int. J Adv Struct Eng 6 (4), pp 105-119. 2014

8. ASTM. Annual Books of ASTM Standards, Section 3: Metals Test Methods and Analytical Procedures. (American Society for Testing and Materials, Philadelphia, 1991).

9. C.G. Salmon, J.E. Johnson, F.S. Malhas. Steel Structures: Design and Behavior. 5th Ed. (Prentice Hall Indiana, US, 2008).

10. Indonesian National Standard for Cold-formed Steel Structures (in Indonesian), SNI 7971, 2013.

11. Australian/New Zealand Standard for the Design of Cold-formed Steel Structures, AS/NZS 4600, 2005. 